\title{
A GENERAL FREE CASH FLOW THEORY OF CAPITAL STRUCTURE
}

\author{
Tomáš BUUS \\ Department of Corporate Finance, Faculty of Finance and Accounting, University of \\ Economics Prague, W. Churchill Sq. 4, 13067 Prague 3, Czech Republic \\ E-mail:buust@vse.cz
}

Received 13 October 2012; accepted 18 January 2013

\begin{abstract}
This paper provides general framework for handling time-varying cost of capital, leverage, tax rates, and capital values in a dynamic free cash flow theory of capital structure. That enables efficient analysis of the recent competing theories of capital structure. After including the costs of financial distress and risk premium of debt in the cash flow model, this paper provides a new look at cost of tax shield from the point of view of risk-return relationship. Cost of tax shield is not constant, but depends on leverage and is mostly between cost of assets and cost of debt. Moreover the simulation of firm value and capital structure in presence of taxes, risk, and growth shows that unique optimal leverages exist for each combination of the above factors. The risk-enhanced cash flow theory can explain both the observations, which support pecking order theory, free cash flow theory and tradeoff theory of capital structure. Moreover it fits some evidence, which resists these theories: highly leveraged low growth companies and moderately leveraged large profitable companies.
\end{abstract}

Keywords: capital structure, cash flow, cost of capital, tax shield, leverage, business valuation, cost of equity, cost of debt, theory.

JEL Classification: H21, H22, H30, C67, D51, F41.

\section{Introduction}

Free cash flow (FCF) theories of capital structure suffer from circularity, static nature and inability to account properly for growth and risk. Use of dynamic FCF model of capital structure in this paper provides generalized formulas for WACC and cost of equity, and allows us to account for growth while assessing the cost of capital (COC) and to analyze the preceding FCF theories of capital structure. Addition of risk analysis, especially cost of financial distress (CFD), free of disputable assumptions, helps to determine general relationships between COC. Results of this paper provide link between the main groups of capital structure theories: static tradeoff, FCF, and pecking order theories despite some remaining problems, which are inherent to FCF theories of capital structure in general. 
The preceding FCF models, as described or developed by Ruback (2002), Fernández (2004), Qi (2010), or Barbi (2012) result in cost of tax shield equal to either cost of unlevered equity (assets) or cost of debt. They also either imply the irrelevance of capital structure policy or corner solution. However capital structure matters in different ways at different types of companies. The missing links between different capital structure theories are risk and growth. Frank and Goyal (2003) show that pecking order theory cannot explain the high share of equity at small and young companies, but it performs well at large firms. On the other hand tradeoff theory works well in some cases according to Frank and Goyal (2009), but cannot explain the low leverage at blue chip companies. The pecking order theory states that companies regulate debt level by mix of internal financing and debt, and issue shares at the last. The presented model shows that additional dollar of debt increases leverage more rapidly at higher-than-optimum leverages than at below-optimum leverages. Then the capital value shrinks very fast after reaching the optimal leverage, except for the low-growth-low-risk-low-tax companies (e.g. REITs). That fits the observation that companies use the expensive equity financing as the last option.

\section{Time-varying cost of capital and capital structure}

This paper builds on a capital structure CF theory, which enables time-varying COC, $\mathrm{CF}$ and leverage. After developing the mathematical apparatus used in this paper I made thorough inspection of English-written literature. Qi (2010: 172) states, "Finally we note that the choice of the discount rate... in determining VTS (value of tax shields, note by author) .... is largely based on arguments for certain special cases, i.e., fixed debt and constant leverage ratio. So far, there has been no rigorous theoretical framework for how to handle VTS, especially for more complicated cases." The same findings can be done by inspection of the theories of tax shield value cited in Fernández (2004). Some signs of treating time-variant CF start to emerge in English-written capital theory literature recently at Barbi (2012), but Barbi (2012) keeps still the other variables (esp. COC) constant.

Let $X$ be the value of any of the appropriate types of capital: equity $E$ (leveraged), debt $D$, assets (total capital at debt-free firm) $U$, tax shield $T$ or total capital (value of firm) $C$, and

$$
C=D+E=U+T
$$

(i.e. $X \in\{E, D, T, U, C\}$ ). At the expense of number of variables I introduce and treat the tax shield and its cost to show 1) that there is interdependence between variables, and 2) how different assumptions (often hidden) have influenced the results of the previous papers.

Let $\varepsilon_{X}$ be the CF paid to owners of capital $X$ and $r_{X}$ the rate of return required by them, before personal income tax, and after corporate income tax. For any kind of capital the sum of income $\varepsilon_{X, \tau}$ in period $\tau \in \mathbb{N}$ (natural number) and the value of capital at the end 
of that period $X_{\tau+1}$ is equal to the value of capital at the beginning of that period $X_{\tau}$ plus the required return $X_{\tau} r_{X, \tau}$ :

$$
X_{\tau}\left(1+r_{X, \tau}\right)=X_{\tau+1}+\varepsilon_{X, \tau}
$$

Based on (2) we can express $\varepsilon_{X, \tau}$ :

$$
\varepsilon_{X, \tau}=X_{\tau}\left(1+r_{X, \tau}\right)-X_{\tau+1} .
$$

As equations (2) and (3) are recurrence (or in other words difference) equations, they are valid not only for one period $\tau$, but for any row of subsequent periods. We can rearrange (2) for $K ; K \in \mathbb{N}$ subsequent periods and $X \in\{E, D, T, U, C\}$ :

$$
X_{\tau}=\sum_{n=o}^{K} \frac{\varepsilon_{X, \tau+n}}{\prod_{j=0}^{n}\left(1+r_{X, \tau+j}\right)}+\frac{X_{\tau+K+1}}{\prod_{j=0}^{K}\left(1+r_{X, \tau+j}\right)} .
$$

COC can vary, i.e. $\underset{j \in \mathbb{N}}{\exists}\left(r_{X, \tau} \neq r_{X, \tau+j}\right)$, as well as for constant CF i.e. $\underset{n \in \mathbb{N}}{\exists}\left(r_{X, \tau} \neq r_{X, \tau+n}\right)$, thus also $\underset{n \in \mathbb{N}}{\exists}\left(X_{\tau} \neq X_{\tau+j}\right)$. If e.g. $90 \%$ of yearly CF comes in January, it is not the same situation as if company gets those $90 \%$ of CF in December. Therefore I do not define the length of period $\tau$, which can be short enough to marginalize the problem of changes of $\mathrm{CF}$ intensity, capital values, required return rate changes, and tax rate changes during any of the periods $1 \ldots K$. Meaning of (3) can be illustrated on debt. Product $D_{\tau} r_{D, \tau}$ is interest accrued. If no interest is paid $\left(\varepsilon_{D, \tau}=0\right)$ and all is added to the principal, then $D_{\tau+1}=D_{\tau}\left(1+r_{D, \tau}\right)$. Similarly if $\varepsilon_{D, \tau}>D_{\tau} r_{D, \tau}$, then, $D_{\tau+1}<D_{\tau}$. Similar cases can be illustrated on equity.

The sum of values of all types of capital equals the value of firm $(\oplus$ means exclusive or):

$$
C_{\tau}=\sum_{X \in\{E, D \oplus T, U\}} X_{\tau}
$$

The same has to hold in the case of CF:

$$
\mathcal{E}_{C, \tau}=\sum_{X \in\{E, D \oplus T, U\}} \mathcal{E}_{X, \tau} .
$$

After substitution of (3) into (6) for $X \in\{E, D \oplus T, U\}$ we get:

$$
\left(1+r_{C, \tau}\right) C_{\tau}-C_{\tau+1}=\sum_{X \in\{E, D \oplus T, U\}}\left[\left(1+r_{X, \tau}\right) X_{\tau}-X_{\tau+1}\right]
$$

Then let us subtract (5) at time $\tau$ from (7) and add (5) at time $\tau+1$ to get:

$$
r_{C, \tau} C_{\tau}=\sum_{X \in\{E, D \oplus T, U\}} X_{\tau} r_{X, \tau} .
$$


Now divide (8) by $C_{\tau}$ to get weighted average cost of capital (WACC) $r_{C, \tau}$ :

$$
r_{C, \tau}=\sum_{X \in\{E, D \oplus T, U\}} \frac{X_{\tau} r_{X, \tau}}{C_{\tau}},
$$

which can be rewritten with respect to the composition of capital (1):

$$
r_{C, \tau}=r_{E, \tau}+\frac{E_{\tau}}{C_{\tau}}+r_{D, \tau} \frac{D_{\tau}}{C_{\tau}}
$$

Equation (10) does not tax the return to debt, compared to the textbook WACC formula. In fact the taxation of return to debt is artificial - in practice the interest tax shield manifests itself by CF increase, not by COC decrease. Because of $X \in\{E, D \oplus T, U\}$ and (9), also:

$$
E_{\tau} r_{E, \tau}+D_{\tau} r_{D, \tau}=U_{\tau} r_{U, \tau}+T_{\tau} r_{T, \tau}
$$

Substituting $X \in\{E, D \oplus T, U\}$ instead of general $X_{\tau}$ in (5) and rearranging, we get:

$$
U_{\tau}=-T_{\tau}+E_{\tau}+D_{\tau} .
$$

Substituting (12) for $U_{\tau}$ in (11) and rearranging yields:

$$
r_{E, \tau}=r_{U, \tau}+\left(r_{U, \tau}-r_{D, \tau}\right) D_{\tau} / E_{\tau}-\left(r_{U, \tau}-r_{T, \tau}\right) T_{\tau} / E_{\tau} .
$$

The same applies to additive risk premiums in $r_{X, \tau} ; X \in\{E, D \oplus T, U\}$. In the Sharpe (1964) or Ross (1976) mean-variance risk-reward world the equation (13) would result in:

$$
\beta_{E, \tau}=\beta_{U, \tau}+\left(\beta_{U, \tau}-\beta_{D, \tau}\right) D_{\tau} / E_{\tau}-\left(\beta_{U, \tau}-\beta_{T, \tau}\right) T_{\tau} / E_{\tau} .
$$

with non-zero $\beta_{D, \tau}$ worth mentioning (Davis 2005).

We can also see in (13), what are the necessary assumptions to reach the "standard" or "textbook" WACC formula, applicable to FCFF. For definition of FCFF see Bucher et al. (2002). Respecting the definition of FCFF (denoted $\varepsilon_{C, \tau}^{*}$ ), in contrast to capital cash flows (CCF, see Ruback 2002):

$$
\varepsilon_{C, \tau}^{*}=\varepsilon_{E, \tau}+\varepsilon_{D, \tau}-t r_{D, \tau} D_{\tau},
$$

it is possible to reach the WACC equation:

$$
r_{C, \tau}^{*}=r_{E, \tau} E_{\tau} / C_{\tau}+\left(1-t_{\tau}\right) r_{D, \tau} D_{\tau} / C_{\tau}
$$


using the above algorithm if and only if $\underset{X \in\{E, D, C\}}{\forall}\left[X_{\tau+1}=(1+g) X_{\tau}\right] ; g \in \mathbb{R}$ and $t_{\tau}=t_{\tau+1}$ (note that growth rate $g$ is the same for $X \in\{E, D, C\}$ ). This is in concert with Massari et al. (2007), who find the standard WACC formula valid even in steady growth cases (constant capital structure). The use of interest tax shield variables $T_{\tau}$ and $r_{T, \tau}$, enables analysis of assumptions used by different FCF theories of capital structure. $T_{\tau}$ is the present value of future tax savings realized due to interest accrued to debt (4). Interest payable, not interest paid, reduces the tax base in many jurisdictions (incl. Europe, US). By its nature $T_{\tau} \geq 0$, and $\varepsilon_{E, \tau} \geq 0$ for every $\tau$.

Let us examine the nature of $\varepsilon_{T, \tau}$. Tax shield cannot be pre-paid, drawn or repaid, contrary to other types of capital, as the tax laws in most countries limit the tax-deductibility of the cots to the period, when the costs accrued. At the same time EBIT can be below zero, so that it is not possible to realize any interest tax shield. Moreover the tax deductibility of the past losses is limited in some jurisdictions. To be simple, no carry-forward of tax losses is assumed, thus

$$
\mathcal{E}_{T, \tau}=\min \left(\max \left(0, E B I T_{\tau}\right), r_{D, \tau} D_{\tau}\right) t_{\tau} .
$$

Otherwise we would need a separate (probably option-based) model for assessment of the value of the interest-payable-part of losses and its carry-forward capacity. With possibility to carry forward losses, (17) would be more complicated, but there would still be two limiting factors: EBIT and interest accrued.

\section{Financial distress and risk-return framework}

The most important limiting factor of up-to-date CF theories of capital structure is fact that the more risky equity (the more levered equity), the higher rate of return, but debt is assumed to be riskless, or at least having leverage-independent rate of return. If the $r_{U, \tau}$ is higher than the $r_{D, \tau}$ at low leverages, then the risk of $U_{\tau}$ and risk of $D_{\tau}$ at $100 \%$ debt financing would have to differ to obey the no-cost-of-bankruptcy assumption (Modigliani, Miller 1958). Of course $r_{D, \tau}$ is not constant with respect to leverage (Carlson, Larzak 2011), i.e. risk of $U_{\tau}$ would have to depend on financing. Up-to-date CF theories of capital structure do not handle $r_{T, \tau}$ well. We see mostly leverage-independent $r_{T, \tau}$ or regime-switching models like Ruback (2002). We need to introduce cost of financial distress (CFD) in the above mathematical apparatus.

CFD can be related partly to the value of capital alone, and partly to the value of assets (cp. Almeida, Philippon (2007) extensive literature review). But how to distinguish the financial distress cost from the loss of value of assets? When assets start to lose their earnings capacity, CFD is not usually observable in the form of sales decrease yet. But CFD become observable even at low leverages in other forms - credit spreads grow with growing leverage, as Collin-Dufresne et al. (2001) show, and also closely correlate with equity premium, cp. (Chen et al. 2009). CFD make the $r_{D, \tau}$ strictly increasing function of leverage, as observed by e.g. Almeida and Philippon (2007). They report 
risk-adjusted CFD as a fraction of assets value, besides the credit spreads. CFD probably practically apply by trimming the $\mathrm{CF}$, as well as by use of risk premium in COC, as evident from Andrade, Kaplan (1998) or Korteweg (2010). Moreover, if one re-leverages or de-leverages $r_{E, \tau}$, then either $r_{E, \tau}$ or $r_{U, \tau}$ do not match the risk profile of $r_{D, \tau}$ if one does not adjust $r_{D, \tau}$ alongside the leverage. Cost of debt $r_{D, \tau}$ is known, but just for the particular leverage. Is it correct to count for $r_{U, \tau}$ estimation with $r_{D, \tau}$ of indebted or debt free company? Estimate of $r_{U, \tau}$ from leveraged firm $\left(D_{\tau} / E_{\tau} \gg 0\right)$ data yields $r_{U, \tau}$ inconsistent with $r_{D, \tau}$ observed at $D_{\tau} / E_{\tau} \rightarrow 0$. Estimate of $r_{E, \tau}$ at leveraged firm from debt-free firm $\left(D_{\tau} / E_{\tau} \rightarrow 0^{+}\right) r_{U, \tau}$ yields $r_{E, \tau}$ inconsistent with $r_{D, \tau}$ observed at $D_{\tau} / E_{\tau}>>0^{+}$.

To reflect CFD consistently let us replace $U_{\tau}, r_{U, \tau}$ and $\varepsilon_{U, \tau}$ by capital less interest tax shield $\left(C L T_{\tau}\right)$, cost of $C L T_{\tau}$ (i.e. $\left.r_{C L T, \tau}\right)$ and by CF to $C L T_{\tau}$ (i.e. $\varepsilon_{C L T, \tau}$ ). The $r_{C L T, \tau}$ is a growing function of $D_{\tau} / E_{\tau}$ and $r_{U, \tau}$. Another reason for introduction of $C L T_{\tau}$ and $r_{C L T, \tau}$ is the influence of financial distress on both the risk perception and expectations of future sales and profits, cp. Andrade, and Kaplan (1998) or Korteweg (2010). Moreover $r_{C L T, \tau}$ and $C L T_{\tau}$, are easier to derive than $r_{U, \tau}$ and $U_{\tau}$, if CFD exist. $D_{\tau}$ and $E_{\tau}$ are observable, and evaluation of $T_{\tau}$ with $C L T_{\tau}$ is as possible as with $U_{\tau} . C L T_{\tau}, \varepsilon_{C L T, \tau}$, and $r_{C L T, \tau}$ are endogenous. Thus (11), (12), and (14) yield:

$$
\begin{gathered}
E_{\tau} r_{E, \tau}+D_{\tau} r_{D, \tau}=C L T_{\tau} r_{C L T, \tau}+T_{\tau} r_{T, \tau}, \\
C L T_{\tau}+T_{\tau}=E_{\tau}+D_{\tau}=C_{\tau}, \\
r_{E, \tau}=r_{C L T, \tau}+\left(r_{C L T, \tau}-r_{D, \tau}\right) D_{\tau} / E_{\tau}-\left(r_{C L T, \tau}-r_{T, \tau}\right) T_{\tau} / E_{\tau} .
\end{gathered}
$$

The same applies to additive risk premiums in $r_{X, \tau} ; X \in\{E, D \oplus T, U\}$. Return rate $r_{X, \tau}$ in (20) can be replaced by $\beta_{X, \tau}$ in the Sharpe (1964) or Ross (1976) mean-variance risk-reward world.

In most CF capital structure models $r_{X, \tau}, X_{\tau}, \varepsilon_{X, \tau} ; X \in\{E, D \oplus T, U\}$ are expected values, or averages, if it comes to maximum likelihood estimators (MLE). When I further treat $r_{X, \tau}, X_{\tau}, \varepsilon_{X, \tau} ; X \in\{E, D \oplus T, U\}$ as stochastic, I denote the MLE $\overline{r_{X, \tau}}, \overline{X_{\tau}}, \overline{\varepsilon_{X, \tau}}$. I cannot avoid mixing sections of stochastic and deterministic $r_{X, \tau}, X_{\tau}, \varepsilon_{X, \tau}$, because I need to introduce risk in the otherwise (usually) deterministic model. Without risk any solution of deterministic FCF capital structure model is possible due to too many unknowns. The subsequent part of this section treats all variables as stochastic.

Staying in Sharpe (1964) or Ross (1976) mean-variance risk-reward world and assuming that there is a common source of risk for any kind of capital in a company risk of assets - therefore correlation of market portfolio with returns to $E, D, T, U$ is the same, we get

$$
\underset{X, Y \in\{E, D \oplus T, U\}}{\forall}\left[\left(\overline{r_{X, \tau}}-r_{f, \tau}\right) / \sigma\left(r_{X, \tau}\right)=\left(\overline{r_{Y, \tau}}-r_{f, \tau}\right) / \sigma\left(r_{Y, \tau}\right)\right] .
$$

where $r_{f, \tau}$ is risk-free rate of return and naturally $\sigma^{2}\left(r_{f, \tau}\right)=0$. What is the source of risk? From the point of view of time $\tau, X_{\tau}$ is known. Expressing $r_{X, \tau}$ from (2), it emerges that 


$$
\sigma^{2}\left(r_{X, \tau}\right)=\sigma^{2}\left(X_{\tau+1}+\varepsilon_{X, \tau}-X_{\tau}\right) / X_{\tau}^{2}
$$

where $X_{\tau+1}+\varepsilon_{X, \tau}-X_{\tau}$ is net income in the case $X \equiv E$, and interest accrued if $X \equiv D$. Let us assume usual $\sigma^{2}\left(\varepsilon_{X, \tau}\right)=\sigma^{2}\left(\varepsilon_{X, \tau+1}\right), \operatorname{cov}\left(\varepsilon_{X, \tau}, \varepsilon_{X, \tau+n}\right)=0$. If $K=\infty$ in (4), then it is also easy to see that $\operatorname{cov}\left(\varepsilon_{X, \tau}, r_{X, \tau}\right)=0$. In long term company cannot distribute more profit than is the net income. All together $\varepsilon_{X, \tau}$ is the only source of risk in our model. If $\varepsilon_{X, \tau}$ is deflated, so that we can denote its generating process as stationary, then (22) yields:

$$
\sigma\left(r_{X, \tau}\right) / \overline{r_{X, \tau}}=\sigma\left(\varepsilon_{X, \tau}\right) / \overline{\mathcal{E}_{X, \tau}} .
$$

The tax shield is a special case, because it depends on interest accrued(not paid) and its upper bound is tax from EBIT, i.e. $t_{\tau}\left(U_{\tau+1}+\varepsilon_{U, \tau}-U_{\tau}\right)$. If $\sigma(\alpha) / \bar{\alpha} \equiv \mathrm{V}(\alpha)$, then

$$
V\left(r_{T, \tau}\right) \neq V\left(r_{D, \tau}\right)
$$

contrary to very commonly stated $V\left(r_{T, \tau}\right)=V\left(r_{D, \tau}\right)$, which we would yield if we forgot about the upper limit of the tax shield.

Equation (23) can be used to derive risk of CLT, assets, and tax shield in a FCF capital structure model, because $V\left(r_{X, \tau}\right)$ is not directly observable at these kinds of capital, as they are not traded publicly. However $V\left(r_{E, \tau}\right)$ and $V\left(r_{D, \tau}\right)$ are observable at the capital market.

What is the relation between $r_{D, \tau}, r_{U, \tau}$, and $r_{E, \tau}$ then? Recall that $\varepsilon_{E, \tau}$ is residual item as $\varepsilon_{E, \tau}=\varepsilon_{C, \tau}-\varepsilon_{D, \tau}$, because payments to creditors have priority. To show the consequences, let us demonstrate two cases of indebted company, i.e. $\varepsilon_{D, \tau}>0$ :

1) company has sufficient earning capacity to satisfy creditors: credit spreads are negligible, $V\left(r_{D, \tau}\right) \rightarrow 0^{+}$and change of CCF (i.e. $\varepsilon_{C, \tau}$ ) shifts almost entirely onto equity:

$$
\Delta \varepsilon_{E, \tau} \cong \Delta \varepsilon_{C, \tau}
$$

nevertheless

$$
\mathcal{E}_{E, \tau}<\mathcal{E}_{C, \tau}
$$

Then from (22) it emerges that:

$$
V\left(r_{E, \tau}\right) \geq V\left(r_{C, \tau}\right) \geq V\left(r_{D, \tau}\right)
$$

2): $\overline{D_{\tau}} / \overline{E_{\tau}} \rightarrow \infty$ and company does not have earning capacity to fully satisfy creditors. Then (approximate equalities are used in the case that something is left to share holders):

$$
\Delta \varepsilon_{D, \tau} \cong \Delta \varepsilon_{C, \tau} \text {, and } \mathcal{E}_{D, \tau} \cong \mathcal{E}_{C, \tau} \text {, }
$$


hence

$$
\overline{\mathcal{E}_{E, \tau}} \rightarrow 0^{+}
$$

however

$$
\sigma\left(\varepsilon_{E, \tau}\right) \gg 0
$$

Note that $\overline{\varepsilon_{E, \tau}} \geq 0$ (shareholders usually do not make capital contributions to financially distressed company) so that $\varepsilon_{E, \tau}$ can be described by Pareto distribution. Then $\mathrm{V}\left(r_{E, \tau}\right)>1$ due to $\sigma\left(\varepsilon_{E, \tau}\right)<\overline{\varepsilon_{E, \tau}}$, if $\varepsilon_{E, \tau}$ follows Pareto distribution type I, III or IV. Then again:

$$
V\left(r_{E, \tau}\right) \geq V\left(r_{C, \tau}\right) \geq V\left(r_{D, \tau}\right)
$$

Inequalities (27) and (31) hold for any level of debt, as creditors have priority to shareholders. Because $\varepsilon_{C L T, \tau}$ is influenced by both risk of assets and of debt, we can sum up that:

$$
r_{E, \tau} \geq r_{C L T, \tau} \geq r_{U, \tau} \geq r_{D, \tau}
$$

Inequality (32) seems to be obvious, but many capital theories used in practice, as reviewed by Fernández (2004), produce $r_{E, \tau}<r_{U, \tau}<r_{D, \tau}$ for high leverages and risky debt. One could complain about bond yields as high as $20 \%$. Well, $D_{\tau}<U_{\tau}$ always. Credit spreads do not represent the true risk premium in $r_{D, \tau}$, because credit spreads are estimated using contractual, not really achievable installments and interest payments. However, $\varepsilon_{D, \tau} \leq \varepsilon_{U, \tau}$, otherwise owners (equity holders) would have unlimited liability.

\section{Recent cash flow theories of capital structure}

The above derived framework lets us review selected FCF theories of capital structure. The subsequent section treats all variables in the nature, the reviewed papers do, i.e. mostly in deterministic nature.

Ruback (2002) provides two marginal cases: the $D_{\tau}=D_{\tau+1}$, and $D_{\tau} / E_{\tau}=D_{\tau+1} / E_{\tau+1}$. In the first case he finds $r_{T, \tau}=r_{D, \tau}$, in the latter one $r_{T, \tau}=r_{U, \tau}$, based on analysis of $\beta_{D, \tau}$ and $\beta_{U, \tau}$. Ruback (2002) uses variables constant in time, thus the lower indexes used here for description of his theory have limited validity only to necessary cases. Firstly to the case $D_{\tau}=D_{\tau+1}$ : Ruback (2002: 97) provides equation of $\beta_{E, \tau}$ for $D_{\tau}=D_{\tau+1}$ and finds that $r_{T, \tau}=r_{D, \tau}$. He however assumes $r_{T, \tau}=r_{D, \tau}$ in his equation (19), and implicitly $D_{\tau}=D_{\tau+1}, t_{\tau}=t_{\tau+1}$ and $r_{T, \tau}=r_{D, \tau+1}$, all deterministic. Risk is borne purely by beta in his framework, i.e. $r_{X, \tau}=r_{f, \tau}+\beta_{X, \tau} R P ; X \in\{E, D \oplus T, U\}$, where $R P$ is market risk premium. Ruback starts with $r_{T, \tau}=r_{D, \tau}$. It is inevitable to reach $\beta_{T, \tau}=\beta_{D, \tau}$ then, thus $\beta_{T, \tau}=\beta_{D, \tau}$ cannot be used for justification of $r_{T, \tau}=r_{D, \tau}$, which he unfortunately 
does. The second case examined in (Ruback 2002: 98) is $D_{\tau} / E_{\tau}=D_{\tau+1} / E_{\tau+1} . D_{\tau} / E_{\tau}$ is deterministic again, as well as $t_{\tau}$ and $t_{\tau}=t_{\tau+1}$. Otherwise Ruback (2002) treats $R P$ and $T_{\tau}$ like stochastic, as he bases his proofs on betas. If one considers $T_{\tau}$ stochastic, he/she has to allow for stochastic $t_{\tau}, r_{D, \tau}, D_{\tau}$, and $D_{\tau} / E_{\tau}$. Moreover Ruback (2002) assumes $D_{\tau}=$ $\delta U_{\tau}$, where $\delta$ is fixed ratio. Because of $r_{X, \tau}=r_{f, \tau}+\beta_{X, \tau} R P$ and $D_{\tau}=\delta U_{\tau}$, thus implicitly $r_{T, \tau}=r_{U, \tau}$, inevitable conclusion is $\beta_{T, \tau}=\beta_{U, \tau}$. Due to his (often implicit) assumptions he reaches his conclusions regardless of the true risk profile of tax shields. Moreover, under his assumptions of $\beta_{T, \tau}=\beta_{U, \tau}$, deterministic $D_{\tau}=\delta U_{\tau}, t_{\tau}=t_{\tau+1}$, and due to $D+E=$ $U+T$ we would find that $r_{X, \tau}=r_{U, \tau} ; X \in\{E, D \oplus T, U\}$ !

Fernández (2004) wrote beneficial paper, which reviews important COC theories. His theory, keeping my notation of variables, represents equation:

$$
r_{E, \tau}=r_{U, \tau}+\left(r_{U, \tau}-r_{D, \tau}\right)\left(1-t_{\tau}\right) D_{\tau} / E_{\tau}
$$

for the constant perpetuities or constantly growing perpetuities in world without bankruptcy costs (or CFD). Further he finds $T_{\tau}=t_{\tau} r_{U, \tau} D_{\tau} /\left(r_{U, \tau}-g\right.$ ) (but uses variables constant in time). Cooper, Nyborg (2006) write that Fernández (2004) mixes Miles-Ezzell and Modigliani-Miller debt policies. Fernández (2004) assumptions contradict his conclusions. Equation (33) needs $r_{T, \tau}=r_{D, \tau}$ and $T_{\tau}=t_{\tau} D_{\tau}$, cp. eq.(13) in this paper. So there is another objection to his conclusions: Consider $r_{T, \tau}=6 \%$ equal to interest rate, while growth rate of assets (and debt) $g=5 \%$ p.a. The interest accrued increases by $5 \%$ each period due to $5 \%$ increase of $D_{\tau}$. However growth does not increase the value of debt: the higher growth rate, the lower part of interest is paid (or the higher is drawn). With $g=5 \%$ and $r_{D, \tau}=6 \%$ one sixth of interest is paid, i.e. $\varepsilon_{D, \tau}=1 \% D_{\tau}$. Obviously $D_{\tau}=1 \% D_{\tau} /(6 \%-5 \%)$. Let $r_{T, \tau}=r_{D, \tau}$ (necessary for $\left.(33)\right)$. Then $T_{\tau}=\left(r_{D, \tau} D_{\tau} t_{\tau} /\right.$ $\left(r_{D, \tau}-5 \%\right)$, thus $T_{\tau}=1,5 D_{\tau}$, but not $T_{\tau}=t_{\tau} D_{\tau}$. Value of debt is ceteris paribus the same regardless the growth rate, while value of tax shields increases with growth rate, contrary to Fernández (2004) assumptions.

Arzac and Glosten (2005) find that $T_{\tau}<t_{\tau} D_{\tau}$ if all variables are stable in time, especially $D_{\tau}=D_{\tau+1}$ and $t_{\tau}=t_{\tau+1}$. As they assumed $r_{T, \tau}=r_{U, \tau}$, and $D_{\tau}=D_{\tau+1}$, their finding is natural. Their incorrect $r_{T, \tau}=r_{U, \tau}$ stems from their use of "pricing kernel", about which they "need not worry" (ibid: 454). Using not "pricing kernel", but COC, they would find in their equation (12) that by use of the principal repayment both as a part of $\varepsilon_{T, \tau}$ and as a $\Delta E_{\tau}$, they have to assign $r_{U, \tau}$ to this bi-directional and bi-risky CF. Principal repayment has its own risk profile (inherent to debt), no matter of expressing it as part of $\Delta E_{\tau}$, contrary to their assumption. Interestingly the first part of their equation (12) - before the risk-return flaw properly shows that if $D_{\tau}$ decreases, then $T_{\tau}<D_{\tau} t_{\tau}$, and if $D_{\tau}$ increases, then $T_{\tau}>t_{\tau} D_{\tau}$. The above problem of (Arzac, Glosten 2005) approach is evident in their equation (13), where the discount rate for debt (and/or equity) valuation is both $r_{D, \tau}$ and $r_{U, \tau}$ in the same submultiple - that flaws the both the general and special case derivation of $T_{\tau}$ (ibid).

Farber et al. (2006) provide an interesting expression of WACC applicable to FCFF. The assumptions, under which such WACC formula is derivable (constant amounts of capital or constant growth rate implying constant share of debt on capital structure) are 
discussed above. The conclusions derived by Farber et al. (2006) are in line with their assumptions about $r_{T, \tau}$ (ibid: 216, 217). They still provide neither convincing proof nor evidence for $r_{T, \tau}=r_{U, \tau}$ or $r_{T, \tau}=r_{D, \tau}$. Fernández (2007) further examines their conclusions, but builds on findings of Arzac and Glosten (2005). Therefore the same objection can be raised to Fernández (2007) as to Farber et al. (2006).

Qi (2010) provides results similar to (Ruback 2002), although based on comparison of personal and corporate lending and borrowing rates. Qi (2010) concludes that $T_{\tau}=t_{\tau} D_{\tau}$ if individual could lend/borrow at the same rate as a corporation borrows. Furthermore he assumes $D_{\tau}=D_{\tau+1}$. However the personal and corporate lending and borrowing rates have no influence on risk profiles of different kinds of capital. Therefore Qi's (2010) conclusions miss the main driver of risk premium - the risk. However I have to agree with him on criticism of Liu (2009), who splits tax shields into earned and unearned. All tax shields are unearned from the ex-ante point of view, and those, which are earned, were already distributed either as CF or as capital value increase.

Oded et al. (2011) base their reasoning of $r_{T, \tau}=r_{U, \tau}$ for company, which rebalances its debt share on assets, on the perfect correlation between $T_{\tau}$ and $U_{\tau}$. As the company rebalances debt share, it implicitly creates a fluctuation of debt, thus $r_{T, \tau}=r_{U, \tau}$. Accepting the logic of Oded et al. (2011), what would be the risk inherent to equity? If debt fluctuates the same way as assets and tax shield value do, then equity has to do so too, because its share on assets is fixed (cp. their equations (3) and (4)). Then their conclusions (8) and (9) contradict their assumptions. We can also object that for non-constant perpetuities with rebalanced debt $T_{\tau} \neq t_{\tau} D_{\tau} r_{T, \tau} / r_{U, \tau}$. (contrary to their (7)).

Barbi (2012) also implicitly assumes that $r_{T, \tau}=r_{U, \tau}$ (but with constant COC), because he starts derivation of tax shield value as a part of value of unlevered equity, to which $r_{U, \tau}$ is naturally the appropriate rate of return (cp. his equations (13), (14)). The contradiction included in his analysis (p. 254) is that by mixing risk-neutral approach and the classical one he comes to conclusion that tax shield yields risk-free rate of return, but its profile equals risk profile of assets (ibid). There is circularity between tax shield, unlevered capital and total capital (or their cost, respectively), therefore his experimental test show good results despite contradictory assumptions. If one keeps the correct algebra, the (Modigliani, Miller 1963) capital structure framework works in spite of results contradicting assumptions in terms of risk handling. It is worth noting that equation (14) in Barbi (2012) very closely resembles the equation (13) in Arzac, Glosten (2005) and (2) in Fernández (2007), with one little exception: Barbi (2012) found risk-free rate of return more appropriate than cost of debt for the tax shield.

Qi et al. (2012) come very close to the answer of the crucial question: what is the risk profile of tax shields, thus also what is $r_{T, \tau}$. They present findings similar to (17), but they compare EBT (earnings before tax) and total tax deductibles sum. However, the question of interest tax shield usability lies upon comparison of EBIT and interest accrued! Therefore (interest) tax shield usability does not depend on $\sigma\left(\varepsilon_{E, \tau}\right)$, but on $\sigma\left(\varepsilon_{C L T, \tau}\right)$, resp. $\sigma\left(\varepsilon_{U, \tau}\right)$, and on $\sigma\left(\varepsilon_{D, \tau}\right)$. Qi et al. (2012) provide analysis of the probability of realization of tax deductibles (deductible from EBT), not probability of realization of interest (or debt) tax shield. Although it enables them to address the crowding-out of 
non-interest tax shields, it precludes use of their findings for interest tax shield. Furthermore their analysis relies upon assumption $r_{T, \tau}=r_{D, \tau}$ in case of $D_{\tau}=D_{\tau+1}$ and $r_{T, \tau}=r_{U, \tau}$ in case of $D_{\tau} / E_{\tau}=D_{\tau+1} / E_{\tau+1}$. That requires deterministic debt in otherwise stochastic environment. So a step to understanding tax shields risk and return has been done by Qi et al. (2012), but a way is still ahead.

The above review of the most recent substantial contributions to the CF theories ofcapital structure shows the need for closer examination of $r_{T, \tau}$ and influence of CFD. Thorough review of earlier papers (a comprehensive review provides Fernández 2004) would require separate study. There is no way to examine the conclusions about $r_{T, \tau}$ without examination of its risk. As we can see in (13) any rate of return can be at the place of $r_{T, \tau}$, and the whole apparatus will work, but sometimes with weird or extreme results. The reason is mutual dependence between $r_{E, \tau}, r_{U, \tau}$ and $r_{T, \tau}$.

\section{Value of tax shields}

The subsequent section treats all variables as stochastic, if not stated otherwise.

Risk of tax shields can differ from the risk of debt. The $\varepsilon_{T, \tau}$ is described by (17) and equals difference between the $\operatorname{CCF}\left(\varepsilon_{C, \tau}\right)$ and FCFF $\left(\varepsilon_{C, \tau}^{*}\right)$, as shown in (15). Thus 3 factors determine the tax shield: tax rate, interest accrued, EBIT. Let us consider the case $t_{\tau}$ is deterministic, $\varepsilon_{C, \tau}=E B I T_{\tau}$ and tax losses cannot be carried forward. With respect to (17), the expected $\varepsilon_{T, \tau}$ (i.e. $\overline{\varepsilon_{C, \tau}}$ ) is:

$$
\overline{\mathcal{E}_{T, \tau}}=t_{\tau}\left[\int_{0}^{D_{\tau^{r} D, \tau}} \mathcal{E}_{C, \tau} N[\cdot] d \mathcal{E}_{C, \tau}+\int_{D_{\tau^{r} D, \tau}}^{\infty} D_{\tau} r_{D, \tau} N[\cdot] d \mathcal{E}_{C, \tau}\right],
$$

where $N[\cdot]$ is density function of distribution of $E B I T_{\tau}$ (let us consider normal distribution). The difference between (17) and (34) is that (17) is deterministic, but (34) considers stochastic $\varepsilon_{T, \tau}$. Because higher $\varepsilon_{C, \tau}$ decreases $r_{D, \tau}$ through credit spread decrease, but usually increases $D_{\tau}$ due to debt policy, we can assume $\operatorname{cov}\left(\varepsilon_{C, \tau}, D_{\tau} r_{D, \tau}\right) \simeq 0$. Thus we can express $\sigma^{2}\left(r_{T, \tau}\right)$ utilizing the law of total variance and (22) as:

$$
\begin{aligned}
\sigma^{2}\left(\varepsilon_{T, \tau}\right) / t_{\tau}^{2}= & \int_{0}^{D_{\tau} r_{D, \tau}} N[\cdot] d \varepsilon_{C, \tau} \sigma^{2}\left(\varepsilon_{C, \tau} \mid 0<\varepsilon_{C, \tau}<D_{\tau} r_{D, \tau}\right) \\
& +\int_{D_{\tau} r_{D, \tau}}^{\infty} N[\cdot] d \varepsilon_{C, \tau} \sigma^{2}\left(D_{\tau} r_{D, \tau} \mid\left(\varepsilon_{C, \tau} \geq D_{\tau} r_{D, \tau}\right)\right. \\
& +\int_{0}^{D_{\tau} r_{D, \tau}} N[\cdot] d \varepsilon_{C, \tau} \int_{0}^{D_{\tau} r_{D, \tau}} N[\cdot] d \varepsilon_{C, \tau} \sigma^{2}\left\{\overline{\varepsilon_{C, \tau}} \mid\left(0<\varepsilon_{C, \tau}<D_{\tau} r_{D, \tau}\right),\right. \\
& \left.\overline{D_{\tau} r_{D, \tau}} \mid\left(\varepsilon_{C, \tau} \geq D_{\tau} r_{D, \tau}\right)\right\} .
\end{aligned}
$$

Abandonment of the assumption that $t_{\tau}$ is deterministic would require estimation of the product of independent variables (see Goodman (1960)). The last summand of (35) is variance between conditional expectations $\overline{\varepsilon_{C, \tau}} \mid\left(0<\varepsilon_{C, \tau}<D_{\tau} r_{D, \tau}\right)$ and $\overline{D_{\tau} r_{D, \tau}} \mid\left(\varepsilon_{C, \tau} \geq D_{\tau} r_{D, \tau}\right)$. 
If $\overline{D_{\tau} / E_{\tau}} \rightarrow 0^{+}$then $\overline{\varepsilon_{C, \tau}} \geq \overline{D_{\tau} r_{D, \tau}}, \overline{\varepsilon_{D, \tau}} \rightarrow 0^{+}, \sigma\left(D_{\tau} r_{D, \tau}\right) \rightarrow 0^{+}$, i.e. $\sigma\left(\varepsilon_{T, \tau}\right) \rightarrow 0^{+}$and $\overline{\varepsilon_{T, \tau}} \rightarrow 0^{+}$As $\overline{D_{\tau} r_{D, \tau}} \geq 0$ as well as $\overline{\varepsilon_{T, \tau}} \geq 0, \sigma\left(D_{\tau} r_{D, \tau}\right)$ and variance between $\varepsilon_{C, \tau}$ and $D_{\tau} r_{D, \tau}$ determines cost of tax shield at $\overline{D_{\tau} / E_{\tau}} \rightarrow 0^{+}$together with the variance of $\mathrm{t}_{\tau}$. Then $V\left(r_{D, \tau}\right) \leq V\left(r_{T, \tau}\right)$ and if variance of $\mathrm{t}_{\tau}$ and variance between conditional expectations $\overline{\varepsilon_{C, \tau}}$ and $\overline{D_{\tau} r_{D, \tau}}$ were high enough, even $V\left(r_{C, \tau}\right) \leq V\left(r_{T, \tau}\right)$ could occur.

If $\overline{D_{\tau} / E_{\tau}} \rightarrow \infty$ then $\sigma\left(D_{\tau} r_{D, \tau}\right) \rightarrow \sigma\left(\varepsilon_{C, \tau}\right)$ and $\overline{\varepsilon_{C, \tau}} \approx \overline{D_{\tau} r_{D, \tau}}$, but $\sigma\left(D_{\tau} r_{D, \tau}\right)<\sigma\left(\varepsilon_{C, \tau}\right)$ due to priority of creditors to shareholders. Nevertheless $\varepsilon_{C, \tau}$ observations, which influence $\varepsilon_{T, \tau}$, are limited from below (by zero) and from above (by $\overline{D_{\tau} r_{D, \tau}}$ ), thus we miss the tails, which create the significant part of variance. As $\sigma^{2}\left\{\overline{\varepsilon_{C, \tau}}\left|\left(0<\varepsilon_{c, \tau}<D_{\tau} r_{D, \tau}\right), \overline{D_{\tau} r_{D, \tau}}\right|\left(\varepsilon_{c, \tau} \geq D_{\tau} r_{D, \tau}\right)\right\} \rightarrow 0$ due to $\overline{\varepsilon_{c, \tau}} \approx \overline{D_{\tau} r_{D, \tau}}$, most probably $V\left(r_{C, \tau}\right) \geq V\left(r_{T, \tau}\right)$, thus also $V\left(r_{C L T, \tau}\right) \geq V\left(r_{T, \tau}\right)$ at this leverage. That also turns into $r_{C, \tau} \sim r_{T, \tau} \sim r_{C L T, \tau}$.

In spite of the possibility of $\sigma\left(r_{C, \tau}\right) \leq \sigma\left(r_{T, \tau}\right)$ at low leverages, it holds that $r_{C L T, \tau}<r_{T, \tau}$ in most cases (usual leverages) because of (20), as the influence of present value of tax shields on cost of equity (leveraged) has been empirically observed to be negative. Dhaliwal et al. (2006: 714) find, that there is decrease of cost of equity by 46 basis points for each $15 \%$ increase of debt/capital ratio at US stocks in 1982-2004. Period of $1982-2004$ was period of rapid growth rates on the US stock markets, and Dhaliwal et al. (2006) report long term growth forecasts 1 st quartile $7.6 \%$ and 3rd quartile $20 \%$ ! Negative effect of tax rate, or tax rate increase, on cost of equity report also Ahmad et al. (2011), or Mnzava (2009). Another empirical paper wrote Fosberg (2010), who also finds negative reaction of cost of equity to tax shield value increase (ibid: 26). Because Fosberg (2010) estimates value of tax shields as product of tax rate and amount of debt, he underestimates strongly the size of tax shield, which leads to otherwise unexplainably large regression coefficient of present value of interest tax shields (PVITS as he denotes it).

A question remains: what is the value of tax shield? The relative value of tax shield (relative to debt) is decreased by high leverage in two ways: low EBIT compared to interest, and risk of tax shield CF. The first reason is analyzed by Qi et al. (2012), who report the tax shield CF being cranked in similar way as equation (17) would suggest (but they base their analysis on tax deductibles). The second reason, the CF risk, is analyzed above. Due to many parameters, which can influence $\sigma\left(r_{T, \tau}\right)$, the only way to truly examine it is a simulation.

\section{Simulation of capital structure with risky debt and tax shields}

Capital value and COC are simulated based on equations (18), (19), (20), (23) and (34) with a discrete time to assess the effect of cost of financial distress (CFD) on capital structure. The option form of tax shield CF (34) provides similar values of $r_{T, \tau}$ as (17) for the same leverage.

Parameters and assumptions of simulation are: $D_{\tau} / E_{\tau}=D_{\tau+1} / E_{\tau+1}$, i.e. steady growth $g \in$ $\{1 \% ; 4 \%\}$ is deterministic, EBIT $=\varepsilon_{C, \tau} \sim N[\mu, \sigma], \overline{\varepsilon_{C, \tau}}=4, \sigma\left(\varepsilon_{C, \tau}\right) \in\{0.3 ; 0.6\}$, $t_{\tau} \in\{10 \% ; 35 \%\}$ with $\sigma\left(t_{\tau}\right)=3 \%$ in both cases, $r_{f, \tau}=5 \%, r_{U, \tau}=r_{f, \tau}+15 \% \times \sigma^{2}\left(\varepsilon_{C, \tau}\right)$. 
Equation $r_{C L T, \tau}=r_{u, \tau}\left(1-p_{\tau} \mathrm{b}\right)$, where $p_{\tau}$ is probability that $\varepsilon_{C, \tau}<D_{\tau} r_{D, \tau}$ reflects CFD $b \in\{10 \% ; 30 \%\}$. Cost of debt $r_{D, \tau}=r_{f, \tau}+\left(r_{C L T, \tau}-r_{f, \tau}\right) D_{\tau} / C_{\tau} .$. I have tested the whole model also with (17) instead of (34) and $r_{C L T, \tau}=r_{U, \tau}\left(1+\mathrm{b} D_{\tau} / C_{\tau}\right)$ with generally the same results as below. To reflect tax rate variance in tax shield risk, I utilize Goodman's (1960) conclusions. Investors are mean-variance optimizers in the meaning of Sharpe (1964) or Ross (1976), which means that price of systematic risk is constant. Because:

$$
\beta_{X, \tau}=\rho_{X, M} \frac{\sigma\left(r_{X, \tau}\right)}{\sigma\left(r_{M, \tau}\right)}
$$

and correlation between capital $X$ and market portfolio $\left(\rho_{X, M}\right)$, as well as risk of market portfolio $\sigma\left(r_{X, M}\right)$ are not dependent on leverage, simulation also respects equation (21). The simulation includes:

1. low-growth-low-risk companies, some of which skillfully use tax optimization, e.g. real estate developers, or airlines $\left(g=1 \%, \sigma\left(\varepsilon_{C, \tau}\right)=0.3, t=10 \%\right.$, or $t_{\tau}=35 \%, b=10 \%$ ), simulation results are at Figures 1 and 2 .

2. high-growth-high-risk companies, which also have high CFD, e.g. dotcoms, biotechs $\left(g=4 \%, J\left(\varepsilon_{C, \tau}\right)=0.6 t_{\tau}=35 \%, b=30 \%\right)$, simulation results are at Figure 3;

3. low-risk-high-growth companies with relatively stable profits, but good growth prospects, e.g. transnational FMCG (consumer goods), utilities, Google ( $g=4 \%$, $\left.\sigma\left(\varepsilon_{C, \tau}\right)=0.3, t_{\tau}=35 \%, b=10 \%\right)$, simulation results are at Figure 4;

4. high-risk-low-growth companies with unstable profits, e.g. those in shrinking industries $\left(g=1 \%, \sigma\left(\varepsilon_{C, \tau}\right)=0.3, t_{\tau}=35 \%, b=10 \%\right)$, simulation results are at Figure 5 . That allows us to examine some of the anomalies to the traditional capital structure theory: why the most profitable and healthy companies keep so much cash (or use so little net debt, as only debt less excessive cash counts), why the young companies tend to issue shares instead of borrowing, or why all of the theories: CF theories of capital structure, pecking order theory, and static tradeoff theory are confirmed by empirical tests (Harris, Raviv 1999; or Myers 2001).

Use of debt can increase company value by only small amount at the low-growth-low-risk companies. The $r_{T, \tau}$ is very close to $r_{D, \tau}$ in the whole domain of leverage. Due to ability to provide security, the CFD is low and such companies use high leverage to increase the return to equity $\left(r_{E, \tau}\right)$. These companies seldom go public because of high $r_{E, \tau}$. It is worth noting that each point (triangle, cross) on the curves of the value of $C L T_{\tau}, C_{\tau}$ or $r_{D, \tau}$ means increase of debt face value by one unit. Increase of the debt by one unit changes leverage at these companies at low and high leverages similarly, which makes low-growth-low-risk companies, which use tax optimization, flexible even at high leverages.

In case the tax rate becomes high $\left(t_{\tau}=35 \%\right)$, behavior of COC changes at low-growthlow-risk companies. Tax shield brings still quite low advantage due to low growth, but $r_{E, \tau}$ becomes flat until very high leverages. The $r_{T, \tau}$ is very close to $r_{D, \tau}$ again. Such companies still like to use debt, but not as much, as observed at real estate developers 


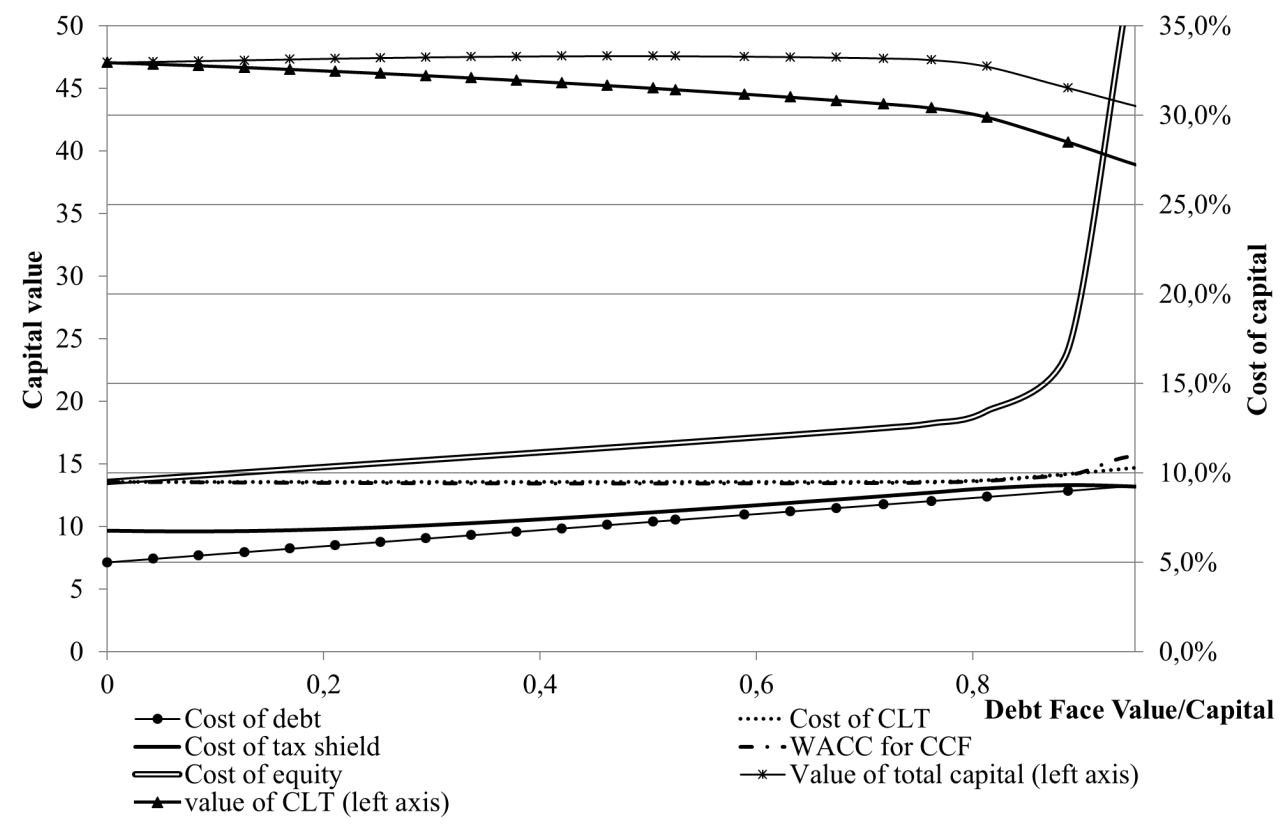

Fig. 1. Low-growth-low-risk companies with tax optimization

$$
g=1 \%, \sigma\left(\varepsilon_{C, \tau}\right)=0.3, t_{\tau}=10 \%, b=10 \%
$$

(and similar) companies (Fig. 1). Quite flat $r_{E, \tau}$ curve makes it more attractive to go public than it was at e.g. real estate developers. The crosses and triangles on the curves of CLT or capital value become less dense after capital value maximum. As each cross or triangle means one unit of debt face value, that means fast decrease of capital value in these areas, and makes such companies unlikely to draw additional debt. Then such a company would like to issue equity to get back to optimal debt levels (Fig. 2).

The high-growth-high-risk companies with high CFD, like dotcoms or biotechs (Fig. 3) cannot gain substantial advantage from debt use, because all COC increase since quite low leverages. There is high $T_{\tau} / C_{\tau}$ ratio at high leverages at these companies. If that is lost due to unfulfilled expectations of EBIT, then indebtedness grows very quickly and equity value drops (Fig. 3). That might be why these companies avoid using debt or use low leverages. High risk and high CFD make the use of debt disadvantageous to these companies.

My model predicts that growth blue chips regulate leverage closely within the optimal territory. The optimal market debt (less cash)/capital ratio is moderate, which can be achieved by low debt and/or high cash. The static tradeoff theory predicts these companies to have high leverages due to high earnings capacity. But our analysis shows that the low difference between $r_{T, \tau}$ and $g$ makes the low leverage optimal. The distance between marks on the curves increases at higher-than optimal leverages (see Fig. 4), but not so strongly as with biotechs and dotcoms (Fig. 3). Flat $r_{E, \tau}$ curve is remarkable 


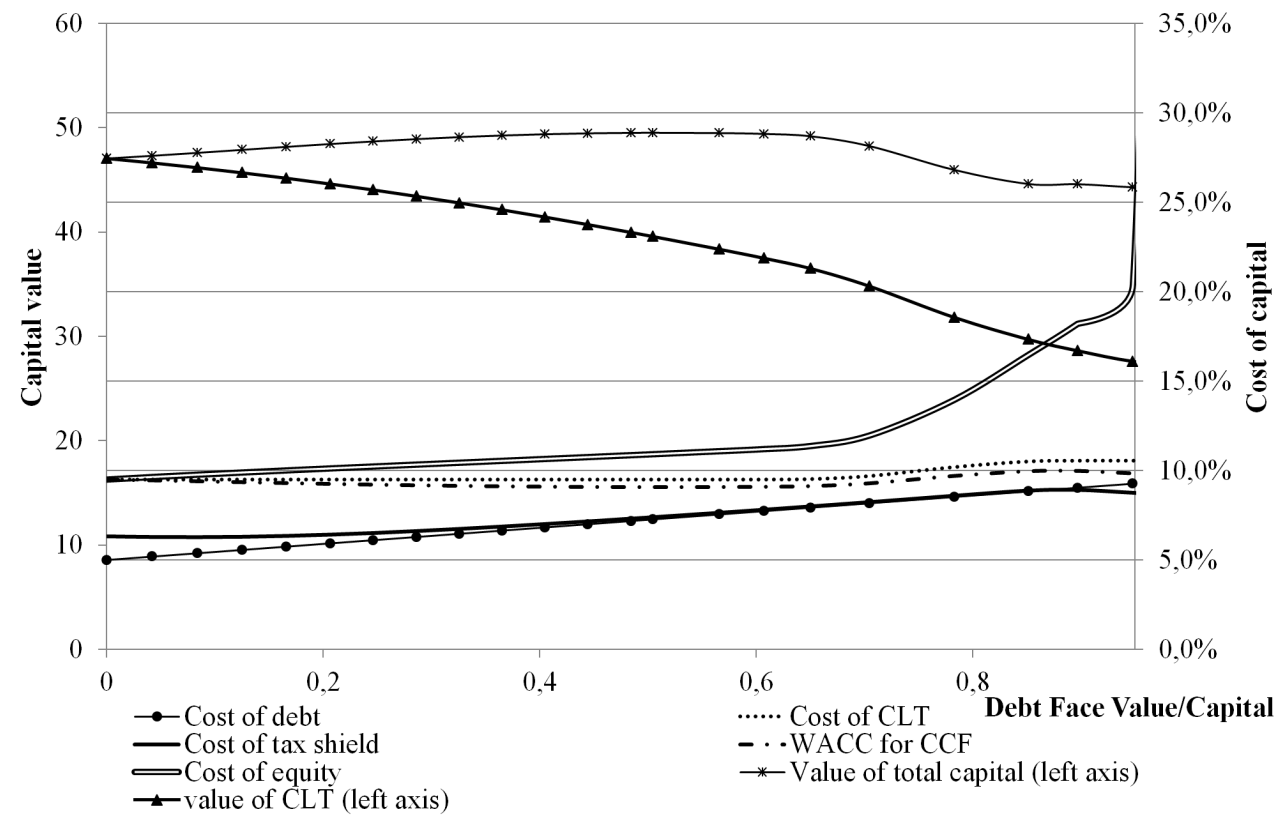

Fig. 2. Low-growth-low-risk companies without tax optimization

$$
g=1 \%, \sigma\left(\varepsilon_{C, \tau}\right)=0.3, t_{\tau}=35 \%, b=10 \%
$$

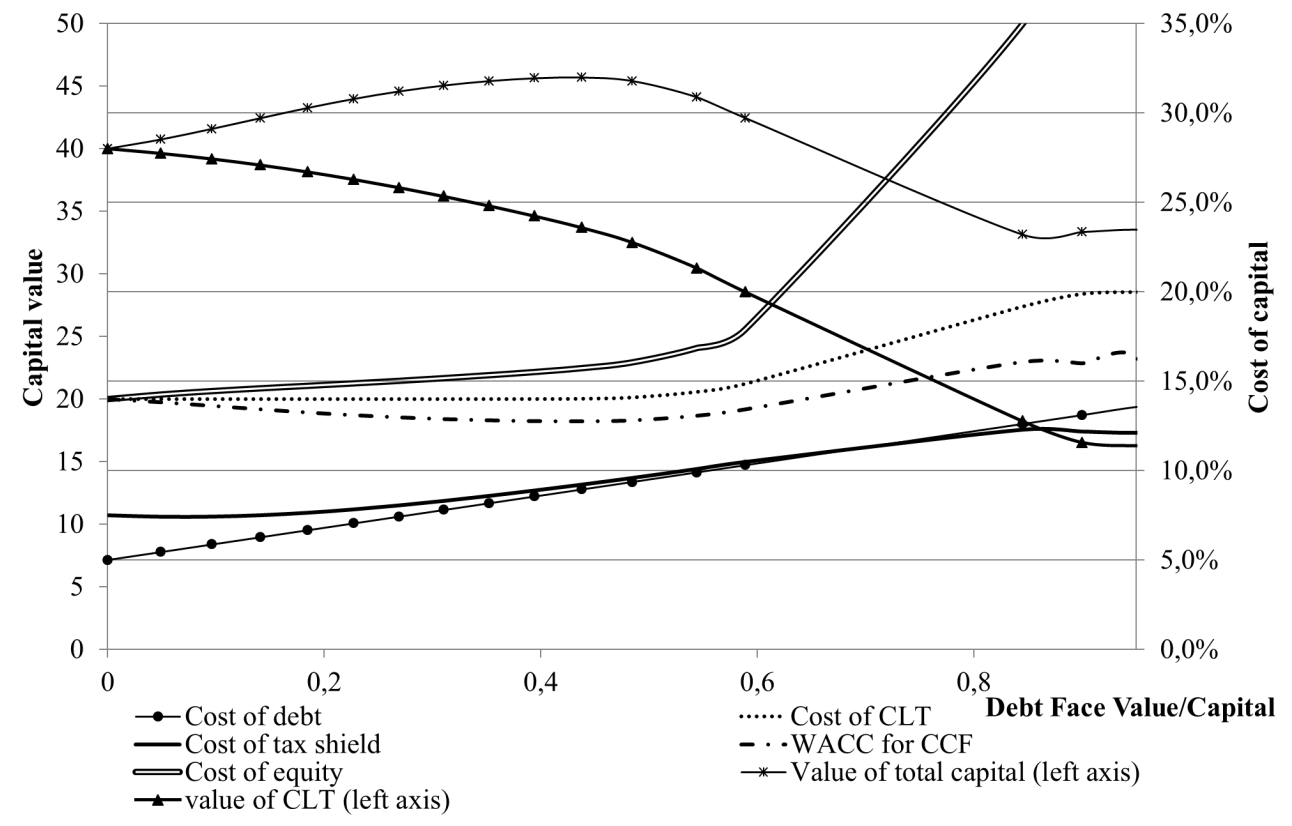

Fig. 3. High-growth-high-risk companies with high CFD

$$
\mathrm{g}=4 \%, \sigma\left(\varepsilon_{C, \tau}\right)=0.6, t_{\tau}=35 \%, b=30 \%
$$




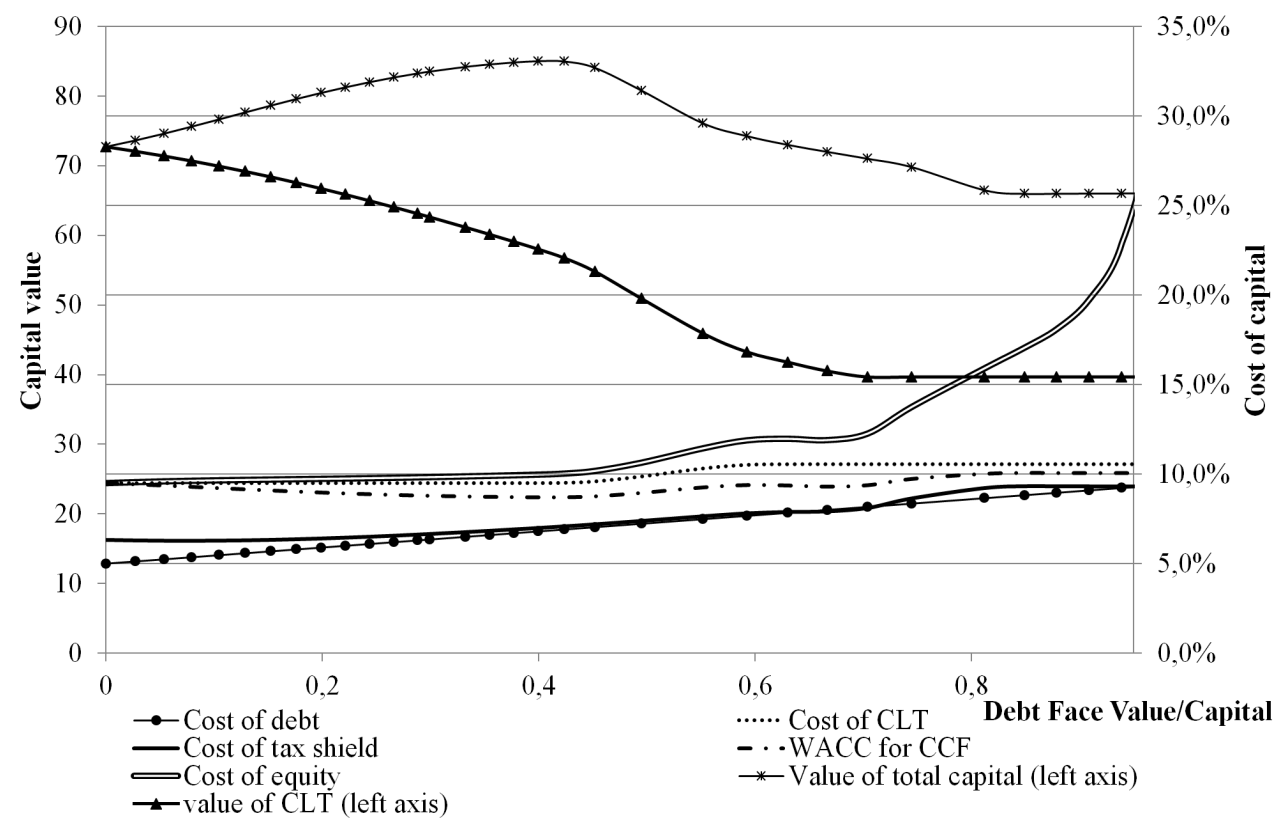

Fig. 4. Growth blue chips

$$
\mathrm{g}=1 \%, \sigma\left(\varepsilon_{C, \tau}\right)=0.3, t_{\tau}=35 \%, b=10 \%
$$

too. The $r_{E, \tau}$ could even decrease (Dhaliwal et al. 2006: 714) with increasing leverage due to high $g$. This case can also explain why some companies accumulate cash while drawing debt. If debtor keeps high cash, then risk is low and $r_{D, \tau}$ stays low too. Yet the equity financing is still affordable even for blue chip companies even after reaching the downward sloping part of $C_{\tau}$ curve.

Finally the high-risk-low-growth companies' case (Fig. 5) shows in the same way as low-growth-low-risk companies did, what drives the shareholders of these companies to high leverage. The high leverage enables to increase return to equity mainly by exploitation of the tax shields. It also shows why they easily become bankrupt. In the simulation it took 3 units of debt face value to get from $40 \%$ to $60 \%$ debt face value/ capital. Just 3 more units of debt are enough to get bankrupt.

The model explains why some companies chose moderate debt levels, thus they fit the static tradeoff theory, as Myers (2001: 88) writes. At the same time it is also able to explain variance of leverages among different industries (see e.g. Harris, Raviv 1991: 334):

1. why companies with valuable assets use high debt levels,

2. why increase of profitability increases leverage (cp. the above results for highrisk-low-growth companies and results for low-risk-low-growth; risk is multiple of EBIT mean so the results can be viewed in a relative way to each other),

3. why lack of growth opportunities increases leverage and high CF decreases it. 


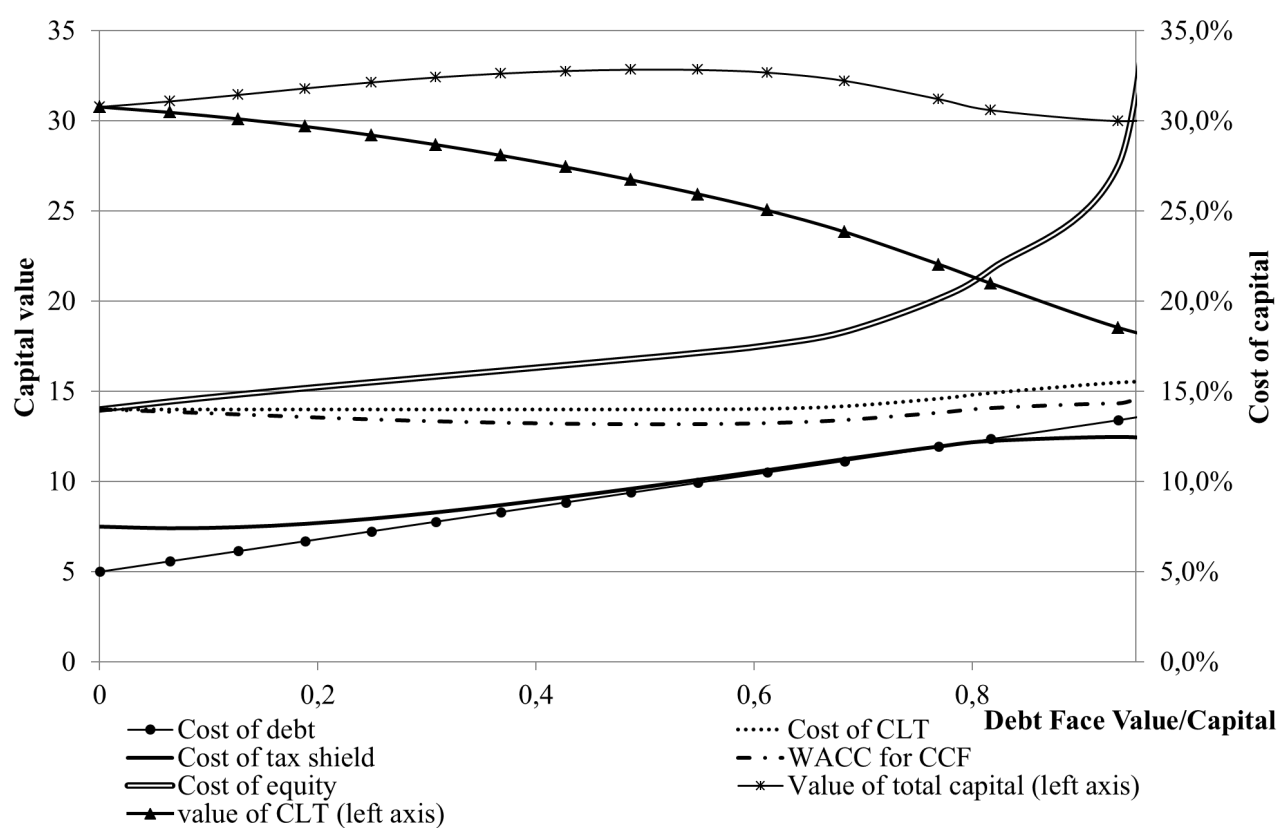

Fig. 5. High-risk-low-growth companies with unstable profits

$$
\mathrm{g}=1 \%, \sigma\left(\varepsilon_{C, \tau}\right)=0.3, t_{\tau}=35 \%, b=10 \%
$$

Theory and evidence on the above relations provides e.g. Harris and Raviv (1991: 343-349). From the point of view of company life cycle my results imply that young companies would prefer internal financing or equity. They would like to issue debt and regulate its level by equity issues as they grow mature and less risky. Finally, the mature companies or those in shrinking industries like debt, and issue shares only as a defense against bankruptcy.

A look at the above model in a dynamic way shows that distressed companies issue equity to get back to optimal capital structure. The last financial turmoil in 2008 and 2009 provides the evidence. Moreover simulations show that $r_{T, \tau}$ does not depend on financing policy, but depends on $r_{D, \tau}, r_{C L T, \tau}$, while the share of these costs in $r_{T, \tau}$ changes with growth and risk.

\section{Discussion}

The simulation of capital value and COC can explain many observed capital structures, and implies that equity issue is rather safety brake at companies with non-corner optimal capital structure. CF theory of capital structure in this paper can explain some observations, which resist tradeoff theory or pecking order theory. Nevertheless this paper needs improvement:

1. The model does not incorporate the option nature of all sorts of capital, although theory moves towards option structure of firm, despite unresolved basic CF model of capital structure. 
2. The shape of capital value curves (as a function of leverage) and $r_{T, \tau}$ are endogenous with respect to $E_{\tau}, D_{\tau}$, and their costs (by the mean-variance framework). The presented theory needs examination in the light of empirically observed costs of equity and debt.

3. The most worrisome problem is that there are two exogenous variables in the simulation, which do not necessarily satisfy the theoretical conditions CAPM (Sharpe 1964) or APT (Ross 1976) variance-mean risk-reward world. In fact standard deviations and normality assumptions could be fine for theoretical proofs and they could also hold in practice due to central limit theorem. Nevertheless it is impossible to simulate all the possible influences (monetary and fiscal policy, interest rates, debt drawing and repayment policies, etc.). If I just assumed that $\varepsilon_{D, \tau}=\min \left(D_{\tau} r_{D, \tau}, U_{\tau} r_{U, \tau}\right)$, then $\sigma\left(r_{C L T, \tau}\right) / \sigma\left(r_{D, \tau}\right)$ becomes meaninglessly high at low leverages because of extremely low $\sigma\left(r_{D, \tau}\right)$ despite proven normal distribution of cash flows (Emery 1981), due to my model's inability to capture variance of $r_{D, \tau}$ caused by other factors, than company's earning capacity volatility. I find no better solution except for the option model of capital structure, which would allow us to examine the risks inherent to different classes of capital even more thoroughly. But that is theme for another paper - we would need to find a consistent risk measure applicable to the option model of a firm.

Contrary to classical CF theories of capital structure, the option theory can imply some benefits of debt even above the value of assets as there is still possibility that something will be left to shareholders (thus shares still have some positive value). In spite of that the basic equations (2), (5), (6) with $C L T_{\tau}$ instead of $U_{\tau},(18),(19),(20)$ have to hold in such case.

A more interesting implication of this paper results, both theoretically and empirically, is the size of tax shield. Within the literature referenced we find even evidence that high growth expectations let the tax shield overweigh the risks, which emerge with higher leverage. Kemsley and Nissim (2002) report the tax shield to be approx. $40 \%$ of debt balance, which is similar to the corporate income tax rates in their data sample (ibid: 2067). That would be too low (they use data for the 1963-1993 period) if the debt is to keep its share on balance sheet and listed companies do not lose their share on U.S. economy, or in other words if interest is supposed to grow by the same rate as GDP. Contrary to that Dhaliwal et al. (2006), Ahmad et al. (2011), Mnzava (2009) or Fosberg (2010) bring evidence that tax shield could possibly overweigh the influence of leverage on COC.

Despite the above objections to my model I hope that it is beneficial in several ways:

1. in promoting the dynamic capital cash flow models, which allow the examination of influence of growth on capital structure, $\mathrm{COC}$ and firm value,

2. in showing the circularities, which baffle the effort for finding the correct riskreturn relationship in the $\mathrm{CF}$ models of capital structure,

3. in incorporation of cost of financial distress in the CF model of capital structure.

My results resemble paper by Bradley et al. (1984), who address the option-like nature of most of the types of capital and show the impact of risk on optimal capital structure. 
Increase of risk (earnings standard deviation) as well as increase of cost of financial distress mostly leads to decrease of optimal debt level in both systems (Bradley et al. $1984 v s$. this paper). The difference is however in mathematical apparatus and its practical usability. Bradley et al. (1984) do not consider growth and do not provide simple system of equations, which would describe cost of capital and capital values. The review of literature on FCF theories of capital structure documents quite well the popularity of Modigliani and Miller (1958)-like models, which this paper also tries to satisfy. By incorporating the risk and growth and by departure from the fixed capital structure and fixed $r_{C L T, \tau}\left(r_{U, \tau}\right)$ FCF theory of capital structure, this paper becomes able to analyze the influence of leverage in more realistic way, compared to the most significant FCF theories of capital structure (for overview see Fernández 2004).

\section{Conclusions}

The dynamic CF model of capital structure described in this paper allows us to examine most of the recent $\mathrm{CF}$ theories of capital structure. Most of them have troublesome circularities or implicit assumptions, which either do not fit reality or contradict other assumptions of those models. Therefore I provide an analysis of riskiness of different types of capital as well as adjustment of the dynamic CF model of capital structure to cost of financial distress. The analysis of risk inherent to tax shields done via simulation in this paper shows that tax shield cost, as well as the optimal financing policy, depends on risk and growth opportunities. Cost of tax shield is mostly between the cost of debt and cost of unlevered equity (or cost of "capital less tax shield", because unlevered equity is observable only at company with zero leverage). Combinations of risk (in a form of CF variance), growth, and tax rate provide suitable explanation for puzzling observations: low-leverage blue chips, quite general applicability of pecking order theory, or use of high leverage at low-growth companies.

\section{Acknowledgments}

This paper is processed as an output of a research project of Faculty of Finance and Accounting, University of Economics, Prague, which is realized within the institutional support VŠE IP100040. I would like to thank anonymous referees, Ike Mathur, and G. William Schwert, who helped me to improve this paper.

\section{References}

Ahmad, F., et al. 2011. Corporate tax rate as a determinant of systematic risk: evidence from Pakistani cement sector, African Journal of Business Management 5(33): 12762-12767.

Almeida, H.; Philippon, T. 2007. The risk-adjusted cost of financial distress, The Journal of Finance 62(6): 2557-2586. http://dx.doi.org/10.1111/j.1540-6261.2007.01286.x

Andrade, G.; Kaplan, S. N. 1998. How costly is financial (not economic) distress? Evidence from highly leveraged transactions that became distressed, The Journal of Finance 53(5): 1443-1493. http://dx.doi.org/10.1111/0022-1082.00062 
Arzac, E. R.; Glosten, L. R. 2005. Areconsideration of tax shield valuation, European Financial Management 11(4):453-461. http://dx.doi.org/10.1111/j.1354-7798.2005.00292.x

Barbi, M. 2012. On the risk-neutral value of debt tax shields, Applied Financial Economics 22(3): 251-258. http://dx.doi.org/10.1080/09603107.2011.613754

Bradley, M.; Jarell, G. E.; Kim, E. H. 1984. On the existence of an optimal capital structure: theory and evidence, The Journal of Finance 39(3): 857-880.

http://dx.doi.org/10.1111/j.1540-6261.1984.tb03680.x

Bucher, M.; Mondello, E.; Marbacher, S. 2002. Unternehmens be wertung mit realoptionen, [Business valuation with real options], Der Schweizer Treuhänder 13(2): 779-786.

Carlson, M.; Larzak, A. 2011. Leverage choice and credit spreads when managers risk shift, The Journal of Finance 65(6): 2323-2362. http://dx.doi.org/10.1111/j.1540-6261.2010.01617.x

Chen, L.; Collin-Dufresne, P.; Goldstein, R. S. 2009. On the relation between the credit spread puzzle and the equity premium puzzle, Review of Financial Studies 22(9): 3367-3409.

http://dx.doi.org/10.1093/rfs/hhn078

Collin-Dufresne, P.; Goldstein, R. S.; Martin, J. S. 2001. The determinants of credit spread changes, The Journal of Finance 56(6): 2177-2207. http://dx.doi.org/10.1111/0022-1082.00402

Cooper, I. A.; Nyborg, K. G. 2006. The value of tax shields IS equal to the present value of tax shields, Journal of Financial Economics 81(1): 215-225.

http://dx.doi.org/10.1016/j.jfineco.2005.07.003

Davis, K. 2005. The systematic risk of debt: Australian evidence, Australian Economic Papers 44(1): 30-46. http://dx.doi.org/10.1111/j.1467-8454.2005.00247.x

Dhaliwal, D.; Heitzman, S.; Li, O. Z. 2006. Taxes, leverage, and the cost of equity capital, Journal of Accounting Research 44(4): 691-723. http://dx.doi.org/10.1111/j.1475-679X.2006.00214.x

Emery, G. W. 1981. Some empirical evidence on the properties of daily cash flow, Financial Management 10(1): 21-28.

Farber, A.; Gillet, R.; Szafarz, A. 2006. A general formula for the WACC, International Journal of Business 11(2):211-218.

Fernández, P. 2004. The value of tax shields is NOT equal to the present value of tax shields, Journal of Financial Economics 73: 145-165. http://dx.doi.org/10.1016/j.jfineco.2002.10.001

Fernández, P. 2007. A general formula for the WACC: a comment, International Journal of Business 12(3): 399-403.

Fosberg, R. H. 2010. A test of the M\&M capital structure theories, Journal of Business \& Economics Research 8(4): 23-28.

Frank, M. Z.; Goyal, V. K. 2003. Testing the pecking order theory of capital structure, Journal of Financial Economics 67(2): 217-248. http://dx.doi.org/10.1016/S0304-405X(02)00252-0

Frank, M. Z.; Goyal, V. K. 2009. Capital structure decisions: which factors are reliably important?, Financial Management 38(1): 1-37.

http://dx.doi.org/10.1111/j.1755-053X.2009.01026.x

Goodman, L. A. 1960. On the exact variance of products, Journal of the American Statistical Association 55(292): 708-713. http://dx.doi.org/10.1080/01621459.1960.10483369

Harris, M.; Raviv, A. 1991. The theory of capital structure, The Journal of Finance 46(1): 297-355. http://dx.doi.org/10.1111/j.1540-6261.1991.tb03753.x

Kemsley, D.; Nissim, D. 2002. Valuation of the debt tax shield, The Journal of Finance 62(5): 2045-2073. http://dx.doi.org/10.1111/0022-1082.00488

Korteweg, A. 2010. The net benefits to leverage, The Journal of Finance 65(6): 2137-2170.

http://dx.doi.org/10.1111/j.1540-6261.2010.01612.x 
Liu, Y. 2009. The slicing approach to valuing tax shields, Journal of Banking \& Finance 33(6): 1069-1078. http://dx.doi.org/10.1016/j.jbankfin.2008.12.002

Massari, M.; Roncaglio, F.; Zanetti, L. 2007. On the equivalence between the APV and the WACC approach in a growing leveraged firm, European Financial Management 14(1): 152-162.

Mnzava, I. D. 2009. The significance of corporation tax as a determinant of systematic risk: evidence using United Kingdom (UK) data, KCA Journal of Business Management 2(1): 44-61. http://dx.doi.org/10.4314/kjbm.v2i1.44410

Modigliani, F.; Miller, M. H. 1958. The cost of capital, corporation finance and the theory of investment, American Economic Review 48(3): 261-297.

Modigliani, F.; Miller, M. H. 1963. Corporate income taxes and the cost of capital, American Economic Review 53(3):433-443.

Myers, S. C. 2001. Capital structure, The Journal of Economic Perspectives 15(2): 81-102. http://dx.doi.org/10.1257/jep.15.2.81

Oded, J.; Michel, A.; Feinstein, S. P. 2011. Distortion in corporate valuation: implications of capital structurechanges, Managerial Finance 37(8): 681-696.

http://dx.doi.org/10.1108/03074351111146175

Qi, H. 2010. Value and capacity of tax shields: an analysis of the slicing approach, Journal of Banking \& Finance 35(1): 166-173. http://dx.doi.org/10.1016/j.jbankfin.2010.07.030

Qi, H.; Liu, S.; Johnson, D. 2012. A model for risky cash flows and tax shields, Journal of Economics and Finance 36(4): 868-881.

Ross, S. A. 1976. The arbitrage theory of capital asset pricing, Journal of Economic Theory 13(3): 341-360. http://dx.doi.org/10.1016/0022-0531(76)90046-6

Ruback, R. S. 2002. Capital cash flows: a simple approach to valuing risky cash flows, Financial Management 31(2): 85-103. http://dx.doi.org/10.2307/3666224

Sharpe, W. F. 1964. Capital asset prices: a theory of market equilibrium under conditions of risk, The Journal of Finance 19(3): 425-442.

Tomáš BUUS. Assistant Professor at the Department of Corporate Finance University of Economics, Prague, Czech Republic.

Tomáš Buus' research interests are valuation, capital structure, transfer pricing and practical aspects of corporate finance. He is CEO in company Expert Group, which provides economic expertises, especially appraisals and CEO in company Academicon, which concentrates on applied economic research, especially regulatory impact assessments. 